\title{
La construcción del otro "del otro lado”. Imaginarios de frontera de jóvenes de Tijuana, México, y Tecún Umán, Guatemala
}

\author{
Amalia E. Campos Delgado*
}

Resumen: los referentes identitarios que construyen los habitantes de las regiones fronterizas no están únicamente relacionados con los que están al otro lado de la línea, sino también con la materialización de la distinción, es decir, con la frontera en sí. A partir de la encuesta para el análisis de imaginarios urbanos y la construcción de mapas mentales, en este artículo se analiza la manera en que las y los jóvenes de las ciudades de Tijuana y Tecún Umán exteriorizan la construcción del "otro", que vive al otro lado de la línea fronteriza. Para estos jóvenes, la frontera con la que conviven es, ante todo, diferenciadora y las pautas son impuestas por el "norte", pero son sus prácticas cotidianas las que la dotan de sentido.

Palabras clave: identidad, alteridad, región fronteriza, imaginarios sociales, frontera, jóvenes.

Abstract: the identity references of the inhabitants of border regions are not only constructed based on the relationships

* El Colegio de la Frontera Norte (Colef). Carretera escénica Tijuana-Ensenada, km. 18.5. San Antonio del Mar, Tijuana, Baja California, C. P. 22560, México. Teléfono (664) 6316300 , extensión 2402. Correo electrónico: amalia.cd@gmail.com 
with those on the other side of the line, but also on the materialized distinction of the border itself. From a survey for the analysis of urban imaginaries and the construction of mental maps, this article analyzes how young men and women in the cities of Tijuana and Tecún Umán externalize the construction of the "other" who lives across the line. For these young people, the border has a differentiating function and the guidelines for crossing it are enforced by the "north", but it is their everyday practices that endow it with meaning.

Key words: identity, otherness, borderland, social imaginaries, border, youth.

\section{Introducción: miradas y contextos}

Las fronteras geopolíticas se deben comprender en tres dimensiones: histórica, física y simbólica. La primera alude al momento sociohistórico en el cual fueron delimitadas, la segunda a la infraestructura de control implementada por los Estados nacionales y la tercera concierne a los referentes de inclusión y exclusión que en ella se materializan (Foucher 1991, 38). A partir de este primer argumento, el presente trabajo busca comprender los referentes simbólicos de la frontera, con la prerrogativa de hacerlo desde la propia mirada de los sujetos. Por su inmediatez, quienes habitan en las regiones fronterizas - por lo general al sur- han generado estrategias para 'vivir en y con la frontera', negociando constantemente con los códigos culturales del 'otro lado' y con los 'nacionales'. Para ellos, la frontera se vive, pero también se interioriza todo lo que ella representa, y son estos referentes interiorizados los que orientan su actuar y apuntalan sus nociones de lo propio y lo ajeno.

En este artículo se analiza la manera en que las y los jóvenes fronterizos de las ciudades de Tijuana, México y Tecún Umán, Guatemala, construyen su mirada sobre el 'otro', que vive al otro lado de la frontera geopolítica. Para lograr este objetivo, el trabajo está 
dividido en tres apartados, los primeros dos son de corte teórico donde se desarrollan las articulaciones de los conceptos de frontera e identidad, y el de identidades juveniles y frontera, y en el tercero se presenta el análisis de algunos imaginarios de frontera y la manera en que se expresan los referentes de inclusión/exclusión.

Al elegir a estas dos ciudades, como los universos espaciales de la investigación, se parte del supuesto de que los habitantes de las ciudades situadas "al sur" de una frontera geopolítica interiorizan de manera distinta los referentes simbólicos de exclusión imbricados en la frontera, que los habitantes de las ciudades localizadas "al norte”. De modo que, cuando se realizó el diseño de esta investigación se partió del supuesto de que, como afirma Charles C. Ragin, el uso del método comparativo permite al investigador examinar patrones de parecidos y diferencias $(2007,178)$. Si bien, a simple vista ambas ciudades tienen infraestructuras de control y características demográficas disímiles, los estudios comparativos han discutido mucho sobre si las condiciones estructurales y variables usadas deben de ser idénticas, sin embargo, los resultados han mostrado que lo sustancial es que ambas funcionen en una relación equivalente (Allardt 1990, 185). En este caso, lo que las hace comparables no son sus condiciones internas, ni la situación en la que viven las y los jóvenes, sino cómo las dos tienen dinámicas fronterizas y asimetrías con su "norte", que se expresan en las interacciones cotidianas.

Tijuana y Tecún Umán -la Tijuanita de Guatemala (Arriola 1995)son ciudades emblemáticas de las relaciones transfronterizas entre Estados Unidos y México, y México y Guatemala, respectivamente. Ambas fronteras fueron delimitadas después de un proceso conflictivo, que culminó con la firma de tratados que aunque no modificaron a corto plazo la dinámica que ahí se llevaba a cabo, sí marcaron el imaginario colectivo. Con la firma delTratado Guadalupe Hidalgo, en 1848, México perdió casi 51 por ciento de su territorio, y a partir del Tratado de Límites entre México-Guatemala, firmado en 1882, el país al sur perdió $27.949 \mathrm{~km}^{2}$. Aun ahora el control fronterizo está dictado por los países al "norte", sin embargo, como se verá más adelante, es en el análisis de lo micro donde se sustentan las relaciones de separación y encuentro. 
Aquí se emplearon estudios de caso, ${ }^{1}$ puesto que el propósito era acceder al conjunto de códigos imbricados en la frontera geopolítica, ya que interesaba hacerlo vía las percepciones de los sujetos. Ante universos espaciales tan disímiles en nivel macro, como lo son Tijuana y Tecún Umán, se determinó que la tipificación etaria sería poco efectiva, pues no respondería ni correspondería con las dinámicas micro que viven los sujetos, pues no están determinadas por la pertenencia a un "grupo de edad", sino a una autoadscripción como joven(es). Ante este panorama, fueron dos los criterios de homogeneidad de los sujetos, en ambos contextos; la autoadscripción de sujetos, dentro de esta categoría social, y la "praxis divergente" (Brito Lemus 2002) de construcción de sus proyectos de vida, es decir, se entiende por joven a quien esté conformando su ideal de futuro en función de la realidad espacial en el que se desenvuelve. De manera que la selección de los sujetos de estudio se realizó según tres lógicas: a) género, b) condición de originarios -ya que el imaginario social es trasmitido vía las instituciones sociales- y c) que hayan cruzado o no la frontera geopolítica. En las figuras 1 y 2 se detallan las características específicas de los entrevistados.

Para acceder a la información se emplearon dos técnicas, y su aplicación se llevó a cabo en dos sesiones de trabajo. La primera fue un cuestionario, con la metodología propuesta por Armando Silva (2006) para la reconstrucción de los imaginarios urbanos. El cuestionario base consta de 54 preguntas, reformuladas de acuerdo con lo observado en los trabajos de campo exploratorio, donde se obtienen datos sobre la ciudad, la construcción significativa de los lugares de memoria, la frontera, los referentes simbólicos de ella, prácticas de cruce y referentes compartidos.

La segunda técnica fue el mapa mental, entendido como una expresión gráfica de "las propiedades de significación conferidas al

\footnotetext{
${ }^{1}$ Los resultados forman parte de un estudio más amplio, que buscaba comprender la expresión de los imaginarios de frontera en la construcción de proyectos de vida de las y los jóvenes fronterizos de ambas ciudades (Campos Delgado 2010). En este artículo se presentarán seis de los diez tipos de imaginarios de frontera desarrollados, el recorte responde a que, debido a sus características, son los que servirán para el análisis de la manera en que las y los jóvenes fronterizos de las dos ciudades están construyendo algunos de sus referentes del "otro".
} 


\section{Figura 1}

Características de los sujetos: Tijuana

\begin{tabular}{|c|c|c|c|l|l|l|l|}
\hline & Edad & Sexo & $\begin{array}{l}\text { Cruce } \\
\text { legal }\end{array}$ & $\begin{array}{l}\text { Origen } \\
\text { de los padres }\end{array}$ & $\begin{array}{l}\text { Nivel } \\
\text { educativo }\end{array}$ & Ocupación & Colonia \\
\hline 1 & 17 & F & No & Distrito Federal & Secundaria & Estudiante & Pípila \\
\hline 2 & 17 & M & Sí & Sinaloa & Secundaria & Estudiante & Pípila \\
\hline 3 & 19 & F & Sí & Hidalgo-Guerrero & Secundaria & Empleado & Capistrano \\
\hline 4 & 20 & F & Sí & Distrito Federal & Universitaria & Estudiante & Playas de Tijuana \\
\hline 5 & 21 & F & No & $\begin{array}{l}\text { Distrito Federal- } \\
\text { Veracruz }\end{array}$ & Secundaria & Desempleado & M. Matamoros \\
\hline 6 & 22 & M & No & Jalisco-Sonora & Universitaria & Empleado & Patrimonial \\
\hline 7 & 24 & F & Sí & Sinaloa-Veracruz & Universitaria & Estudiante & Jibarito \\
\hline 8 & 25 & F & No & Jalisco-Sinaloa & Universitaria & Estudiante & La Mesa \\
\hline 9 & 28 & M & No & Tijuana-Jalisco & Universitaria & Empleado & Mérida \\
\hline
\end{tabular}

Fuente: elaboración propia.

* Para mantener el anonimato de los sujetos se asignaron seudónimos, sólo se utilizó la primera letra del nombre propio real.

\section{Figura 2}

\section{Características de los sujetos: Tecún Umán}

\begin{tabular}{|c|c|c|c|l|c|l|l|}
\hline & Edad & Sexo & $\begin{array}{c}\text { Cruce } \\
\text { legal }\end{array}$ & $\begin{array}{r}\text { Origen } \\
\text { de los padres }\end{array}$ & $\begin{array}{r}\text { Nivel } \\
\text { educativo }\end{array}$ & Ocupación & \multicolumn{1}{|c|}{$\begin{array}{l}\text { Colonia } \\
\text { o aldea }\end{array}$} \\
\hline 1 & 15 & F & No & Ciudad de Guatemala & Home school & Empleado & Colonia Andrade \\
\hline 2 & 16 & M & Sí & Tecún Umán & Primaria & Triciclero & Colonia El Molino \\
\hline 3 & 16 & M & Sí & Tecún Umán & Diversificado* & Estudiante & San Lorenzo \\
\hline 4 & 18 & M & Sí & Tecún Umán & Diversificado & Estudiante & San Lorenzo \\
\hline 5 & 19 & M & No & Tecún-Puerto Ocós & Diversificado & Estudiante & San Lorenzo \\
\hline 6 & 20 & M & Sí & Quetzaltenango & Diversificado & Empleado & El Triunfo \\
\hline 7 & 21 & F & Sí & Progreso-Tecún & Diversificado & Secretaria & Santa Marta \\
\hline 8 & 22 & F & No & Quetzaltenango & Universitaria & Empleada & Miraflores \\
\hline 9 & 25 & F & Sí & Tecún Umán & Universitaria & Empleada & Las Delicias \\
\hline
\end{tabular}

Fuente: elaboración propia.

* Equivalente al nivel preparatoria en México. 
escenario físico-geográfico por las características sociales y culturales ligadas a su historia" (Arruda y Ulup 2007, 168). La relevancia de esta herramienta es que con ella se puede analizar la parte tangible de la representación del imaginario social de frontera, ya que "expresa una realidad social donde la imagen tiene un papel preponderante. La imagen tiene el papel de 'corpus de significantes'. Es donde tiene presencia la dimensión imaginaria de la representación social" (Guerrero 2007, 236).

La realización del mapa mental respondió a la instrucción "dibujar a la frontera”, en una hoja de 33 x 24 cm y, además de un lápiz, a los participantes se les entregaron seis lápices de colores: verde, azul, rojo, amarillo, negro y café. Como lo muestran estudios anteriores, la principal prerrogativa en el uso de esta metodología es que las dimensiones individual y colectiva están presentes en ellos, de modo que permite observar la apropiación y experiencia del sujeto, y a la vez presenta elementos compartidos e interiorizados de la dimensión colectiva de uso y representación del espacio (De Alba 2004, 120; Estébanez 1981, 19).

Una vez que se sistematizó la información recabada, mediante los instrumentos y técnicas descritos, se analizó a través del programa de análisis de datos cualitativos Atlas-ti (Muhr 1991); se generaron 69 códigos, agrupados en cinco familias: infraestructura de control, movilidad, experiencia fronteriza, imaginario de frontera y otros. El procedimiento fue relacionar los elementos de los imaginarios de ciudad y de frontera, proyectados por las y los jóvenes de Tijuana y Tecún Umán, considerando a la frontera como parte del paisaje simbólico. Puesto que, "el valor analítico de los imaginarios es la posibilidad de reconstruir visiones del mundo desde las cuales los sujetos actúan con propósitos y efectos de "realidad"” (Lindón et al. 2006, 14), se profundizó en la forma en que las características históricas de demarcación de la frontera y la infraestructura orientan las cargas simbólicas y usos sociales de la misma y, en consecuencia, la manera en que los sujetos construyen la imagen del "otro", al otro lado de la línea. Con el fin de situar al lector en los universos espaciales de esta investigación, a continuación se presenta una descripción contextual de ambas ciudades. 


\section{Tijuana: "la de terrible belleza"}

Con una superficie de $1393 \mathrm{~km}^{2}$, Tijuana es uno de los puntos de cruce y regreso más conurridos, "sus aduanas y pasos fronterizos oficiales son el Paso Internacional México- Estados Unidos (TijuanaSan Ysidro), la Garita Mesa de Otay y el paso de FFCC" (Nolasco et al. 1992, 28). El municipio colinda al sur con los de Playas de Rosarito y Ensenada, al este con el de Tecate, al oeste con el océano Pacífico y al norte con el condado estadounidense de San Diego, California, con el que se mantiene una estrecha relación transfronteriza, al punto que es muy común escuchar la expresión "lo más bonito de Tijuana es San Diego" (Jaime, entrevistado en Tijuana, en 2009). Según el iI Conteo de población y vivienda (Instituto Nacional de Estadística, Geografía e Informática, INEGi 2005), su tasa de crecimiento anual era de 2.7; tenía 1410687 habitantes, de los cuales 28.5 por ciento eran menores de 15 años; ocupa el primer lugar en el país en "migración internacional" -población que declaró haber vivido en otro país-. En términos generales, "las características accidentadas del terreno producen una mancha urbana irregular, con zonas habitadas en permanente situación de riesgo -las laderas y cañones-; y una distribución desordenada de los asentamientos poblacionales, que se ven en dificultades para acceder a servicios básicos” (Monsiváis Carrillo 2004, 18).

\section{Tecún Umán: "la Tijuanita de Guatemala”}

Tecún Umán es la cabecera municipal de Ayutla, departamento de San Marcos. El municipio tiene 21 mil habitantes, y una "población flotante" aproximada de 30 mil. En 2004, la pirámide poblacional de Tecún Umán representaba una población mayoritariamente "joven" entre los 10 a 19 años en el caso de los varones y de 10 a 29 en el de las mujeres (Cruz Burguete 2006, 256). El municipio de Ayutla colinda al norte con los de Catarina y Malacatán; al sur con el de Ocós, al este con Pajapita y al oriente con los de Suchiate y la frontera del Distrito de Soconusco, en el estado de Chiapas, México. 
Durante la Colonia, el municipio fue cabecera del Curato de Soconusco, desde 1824 hasta los arreglos limítrofes de 1883 formó parte del municipio de Mariscal, después se incorporó al departamento de San Marcos, con la denominación de Puerto Fluvial de Ayutla. Sin embargo, para 1893 se despobló, "debido a que sus habitantes regresaron a su país de origen (México)”, así perdió su título como municipio y se integró como aldea del municipio de Catarina. Recobró el nombramiento 35 años después, al ser repoblado con fuerzas militares y una penal para delincuentes menores reincidentes, y se creó la capitanía del Puerto Fluvial de Ayutla. Poco después, la población de la municipalidad también incluyó empleados de aduanas y trabajadores del International Railways of Centro América. En la década de 1960, tras decretarse como héroe nacional al príncipe guerrero “Tecum Umam”, por decreto presidencial la cabecera municipal tomó su nombre. Debido a la ya habitual relación transfronteriza, en 1974 se inauguró el puente internacional "Dr. Rodolfo Robles”, sobre el río Suchiate (Zúñiga 2010).

En términos formales, según datos de la Encuesta sobre migración en la frontera Guatemala-México (2005), las localidades donde se registra el mayor movimiento laboral y comercial transfronterizo son -del lado guatemalteco-Tecún Umán y El Carmen, y -del lado mexicano- Ciudad Hidalgo y Talismán. Según datos de esta encuesta, 54 por ciento de los flujos sur-norte aluden a estancias de menos de 24 horas, de personas que utilizan en su mayoría el pase local y trabajan en México en la industria o en el área de servicios. El restante 46 por ciento se refiere a estancias de más de un día de trabajadores en suelo mexicano, que son contratados principalmente en el sector agropecuario colindante a Tapachula, Chiapas, y utilizan algún tipo de documento migratorio para cruzar la frontera (Encuesta sobre migración en la frontera Guatemala-México 2007, 23).

\section{Frontera e identidad}

Hablar sobre identidad fronteriza implica un gran reto, porque además de ser un tema controversial, no se puede hablar de que sea una sola. Sin embargo, es posible identificar la presencia de algunos 
referentes identitarios similares entre los habitantes de la región: la frontera geopolítica en sí, acceso o comercialización con productos del 'otro lado' y la necesidad de afirmarse ante un ajeno, no tan lejano y ante un centro político-administrativo no tan ajeno pero sí lejano. La importancia de este espacio es que, como afirma Pablo Vila, "la frontera ofrece una oportunidad única de ver el complejo proceso de construcción de la identidad y su uso constante de los sistemas de clasificación arbitraria que dan sentido a las identidades sociales" (2000, 21, traducción propia).

La carga simbólica de las fronteras se ve proyectada en las construcciones identitarias y relaciones de confrontación 'frente a frente', entre la nación al norte y la nación al sur. Como lo menciona Olga Odgers, en las regiones fronterizas los contrastes culturales son tan intensos y controvertidos, que la construcción de una referencia identitaria para sus habitantes se fundamenta en una reinterpretación del pasado compartido $(2001,13)$. Así, las fronteras no pueden ser separadas de las circunstancias históricas, producto de las cuales fueron constituidas, ya que dichos registros se encuentran resguardados en el imaginario colectivo de la nación entera, pero en especial de los habitantes de la región fronteriza.

Este es el caso de las y los habitantes de las ciudades colindantes a las fronteras México-Estados Unidos y México-Guatemala, para ellos la frontera es una 'ruptura', pues separó territorios y grupos étnicos que antes se encontraban unidos. Para los tijuanenses, -como reza el mensaje sobre la barda que separa Tijuana y San Diego-, la frontera es una "herida abierta". Generación tras generación las y los fronterizos mexicanos han interiorizado las nociones de pérdida y, en función de esto, han "resemantizado" a la frontera y al uso que hacen de ella. Por su parte, para las y los fronterizos guatemaltecos, "la frontera es una barrera que impide que dos países se unan" (Olga, entrevistada en Tecún Umán, en 2010), y si se va más allá, es posible aventurarse a decir que la separación de la región del Soconusco fue el hecho fundamental que no permitió la consolidación de la República Centroamericana, y este evento se encuentra presente en la memoria colectiva. Algunos dicen que la nación mexicana, ante la pérdida del territorio norte, aprovechó e hizo lo mismo con su parte sur (Valenzuela 2005, 236), otros, que un grupo de chiapanecos traicionaron el ideal centroamericano (Luján 1998). 
Al ser elementos materiales retocados por los referentes simbólicos superpuestos en ellos, las fronteras determinan la naturaleza de los grupos a ambos lados, sus afiliaciones, sentimiento de pertenencia o continuidad, y la manera en que interiorizan los procesos de separación y encuentro que en ella se desarrollan. Valenzuela menciona que, en términos generales, son nueve los procesos culturales fronterizos: intersección cultural, vecindad, apropiación cultural, transculturación, innovación, recreación cultural, resistencia cultural, interpretación y translación cultural. Éstos, desde su gestación, han estado teñidos por contigüidad física, metamorfosis, relaciones de poder, resemantizaciones, elementos culturales compartidos, creación, significación y reinterpretaciones (2003, 57-60). Estos son los bastiones de las identidades fronterizas, procesos que, aun sin que los sujetos estén implicados de forma directa en su producción, a partir de su reproducción los integra como parte de la lógica sociocultural fronteriza.

Las fronteras en su dualidad separación/encuentro son zonas de transición y cambio, barreras y a la vez membranas permeables. Esta lógica de relación dicotómica fronteriza responde a que, según Foucher, las comunidades humanas se organizan territorialmente en dos imperativos contradictorios: la búsqueda de seguridad por un lado, que dicta los modos de organización del espacio e impulsa la delimitación y, por otro, el uso de 'oportunidades', que incita al contacto y alienta la apertura $(2008,5)$.

Es en esta relación de contacto, búsqueda y uso de oportunidades donde se instaura la elocuencia de las relaciones transfronterizas, entendiéndolas como interacciones económicas e interpersonales que traspasan y se fundamentan en la presencia de la frontera geopolítica. Y que, según su intensidad, resultan esenciales para el sostén de los lazos sociales, culturales y económicos de la mayoría de las y los habitantes a ambos lados de la frontera (Ojeda 2009, 11; Bustamante 1989, 8; Odgers 2006, 121). Ya que, como afirma Vila, "la frontera no es sólo una, sino múltiple", en tanto que adquiere un significado específico, y es interiorizada de manera distinta por cada sujeto, según sus diversas posiciones dentro de la estructura social $(2008,313)$. 
Para comprender su lógica, las relaciones transfronterizas se deben entender en función de la intensidad y la razón del cruce. Mientras que para algunos puede ser de tipo comercial: "Mi mamá tiene su cocina, y pues depende, va una o dos o a hasta tres veces a la semana a comprar al otro lado, y pues cruza por la balsa o por el puente dependiendo, si sabe que no trae mucha mercancía mejor se sube a un triciclo y pues se va por el puente, $[\ldots]$ aunque pague más de pasaje y haga más viajes en la semana" (Valeria, entrevistada en Tecún Umán, en 2010).

Para muchos otros la razón es laboral: "Nosotros entrábamos a trabajar a las 6:30 [am] y salíamos a las 4:30 [pm], mi tío vivía cerca de mi casa y pasaba por mí a las 4-4:30 y llegábamos a hacer fila. Toda la gente que pasa a esa hora va a hacer lo mismo, si son 300 , 700 personas haciendo fila a pie ya las conoces, porque todos los días a la misma hora, si vas a las 8 , si vas a las 7 , es la misma gente, y a los carros igual, ya reconoces los carros en la fila" (Angélica, entrevistada en Tijuana, en 2009). Para algunos, la razón de cruce es familiar. “Él tenía una esposa del otro lado, y pues nosotros cruzábamos los domingos para que la niña pudiera ver a su papá, porque de otra manera no lo veía. Al niño no lo podía llevar, a él no le gusta mucho cruzar por el río, se pone muy nervioso y prefería quedarse en la casa" (Yazmin, entrevistada en Tecún Umán, en 2009).

La frontera geopolítica y su infraestructura se entiende como un filtro, con índices muy variables de permeabilidad o porosidad, y a la región fronteriza como la periferia de la infiltración, la determinación de apertura. Como afirma Alejandro Grimson, "las fronteras no sólo son construcciones, también son múltiples y cambiantes. Por un lado, la gente se traslada, desplaza y trastoca significados, autonomizando los vínculos entre cultura, identificación y territorio. Por otro lado, símbolos, textos, músicas y objetos viajan aunque las personas y los grupos permanezcan inmóviles, cuestionando por otra vía aquella supuesta imbricación” $(2003,15)$.

Para que la noción de frontera geopolítica entre los habitantes de la región sea interiorizada como frontera simbólica, debe ser mantenida y reproducida a través de prácticas particulares de exclusión y discursos, que hagan hincapié en 'el otro' como fuente de conflicto (Anderson y O’Dowd 1999, 598). Lo cual quiere decir que no 
necesariamente las relaciones y representaciones mutuas entre los habitantes de las regiones fronterizas son del todo cordiales, sin embargo, es a partir de los momentos de tensión cuando se fortalecen los puntos de encuentro y la capacidad de negociación.

En el caso de los habitantes de la región que colinda con Estados Unidos, uno de los elementos identitarios que más los distinguen es "una interpretación distinta de la experiencia lingüística”, que consiste en tomar prestadas palabras del inglés y apropiárselas, y transformarlas "localmente" hasta ser irreconocibles por el hablante de la lengua primaria. "Para los fronterizos mexicanos, este proceso lingüístico de tomar prestadas palabras del idioma 'del otro lado' es en verdad un proceso de reafirmación étnica” (Bustamante 1997, 306).

Las fronteras están destinadas a tener una connotación dual, mientras significan el control, el poder y la exclusión promovida por los Estados-nación, a la vez representan la inclusión, la vinculación con lo ajeno y la coerción regional. Así que, como lo señala Foucher, las fronteras son al mismo tiempo un proyecto de separación y de contacto pero, sobre todo, de diferenciación de las relaciones de continuidad $(1991,39)$.

Según esta lógica, aun con el establecimiento y relativa inmovilidad de la frontera geopolítica, las relaciones e identidades de los que viven allí pueden estar caracterizadas por el cambio y la negociación. Si bien, la línea divisoria no es modificable, las relaciones a través de ella pueden ser objeto de una redefinición constante (Wilson y Donnan 1998, 21). Al entender que son los procesos y atribuciones de los propios sujetos, en relación con la frontera, quienes dan la carga simbólica a la vida cotidiana 'en frontera', se debe entender a "las relaciones fronterizas y transfronterizas, como gramáticas abiertas y polisignificantes que articulan procesos complejos y muchas veces contradictorios, pero inscritos en relaciones estructuradas y estructuras de poder que reproducen las condiciones de subordinación de amplios grupos sociales" (Valenzuela 2003, 55).

Las zonas fronterizas, de acuerdo al análisis de Newman, pueden asumir características de 'regiones de transición' de dos maneras: la primera, permitiendo un movimiento gradual de una norma cultural a otra, partiendo de que la frontera no es una línea rígida, sino 
una zona en sí. La segunda, como lugares en los que el contacto entre los diferentes grupos refuerza la noción de frontera, donde, a pesar de la interacción, no se constituye la transición sino enclaves que están delimitados por las líneas que los separa del mundo exterior $(2006 b, 151)$.

Los habitantes de estos "espacios de excepción" (Torpey 1998, 241), ante la pluralidad de identidades étnicas, se tornan contestatarios de la identidad nacional cimentada en la igualdad. De manera que la membresía no es nacional, sino que más bien existe una negociación de pertenencia constante con el terruño. Por su parte, las segundas generaciones, ya nacidas en las regiones fronterizas, crean un arraigo dual: a la ciudad fronteriza y a la de origen de sus padres, en el que resalta "la ventaja de vivir tan cerca del otro lado" (Lydia, entrevistada en Tecún Umán, en 2010). Por lo tanto, "vivir en una frontera es vivir en el centro de dos mundos, dos conocimientos, dos culturas, dos idiomas, no para asimilarse, entrar de una a la otra, sino para transcruzarse con el poder y conocimiento del vecino. Es decir, ser fronterizo, es hacerse de un ser de dos fronteras, poder vivir fuera de las dos, entender, apreciar y poder celebrar la salvación y maldición de cada una” (Burciaga, citado en Valenzuela 2000, 54).

En la vida de los residentes de los pueblos fronterizos, la frontera es un recurso y una barrera, pero también un recordatorio constante de sus diferencias tanto con las personas del interior de su propia nación, como frente 'al otro', con quien conviven (Donnan y Wilson 2001, 79). En términos generales, no se reconocen como totalmente partícipes de la identidad nacional, pero tampoco consideran fundamental la concomitancia con sus vecinos al norte o al sur de la línea, de manera que son producto de la misma dicotomía continuidad/diferencia impresa en la frontera.

\section{Identidades juveniles en frontera}

La juventud alude a un conjunto de significaciones imbricadas en un contexto histórico, cultural y relacional, que dan cuenta de la manera en que los sujetos "aprehenden al" mundo, más que de la 
manera en que "aprenden del" mundo. Como constructo sociocultural, no se puede entender a la juventud como desarticulada de los procesos históricos, culturales y políticos de la sociedad donde y a través de la cual se significa, ya sea vía procesos de afirmación o de ruptura. En términos generales, "juventud es un significante complejo que contiene en su intimidad las múltiples modalidades que llevan a procesar socialmente la condición de edad, tomando en cuenta la diferenciación social, la inserción en la familia y en otras instituciones, el género, el barrio o la microcultura grupal" (Margulis 2001, 42).

Con el fin de puntualizar la construcción del concepto, Roberto Brito Lemus explica la dicotomía juventud-adolescencia, señalando que el primer término responde a una connotación de orden social y el segundo a una de orden biológico. En este sentido, "el biológico sirve para establecer su diferenciación con el niño y, el social, su diferenciación con el adulto. En síntesis, la pubertad [o adolescencia] responde más directamente a la reproducción de la especie humana, en tanto que, la juventud, apunta de manera más directa a la reproducción de la sociedad" $(1998,3)$. A partir de este razonamiento se entiende que la juventud es una construcción definida culturalmente, cuya base material radica -sin definirla- en la edad biológica.

Sin embargo, la edad, a través de los procesos y códigos culturales en los que está inmerso el sujeto, adquiere "una densidad que no se agota en el referente biológico y que asume valencias distintas no sólo entre diferentes sociedades, sino en el interior de una misma sociedad al establecer diferencias principalmente en función de los lugares sociales que los jóvenes ocupan en la sociedad. La edad, aunque referente importante, no es una categoría cerrada y transparente" (Reguillo 2000, 26). En este orden de ideas, para entender, según una perspectiva sociocultural, los significados y representaciones construidas en torno a la noción de juventud, la delimitación biológica y el criterio etario resultan poco eficaces y representativos de los diversos contextos, escenarios y roles de las juventudes.

Respecto a la construcción histórica del concepto juventud, Rossana Reguillo afirma que la noción 'vigente' es producto del reordenamiento geopolítico de la posguerra, cuando la sociedad apremió la existencia de jóvenes e infantes como sujetos de derechos y 
principalmente de los primeros como sujetos de consumo. Según Reguillo, para la segunda mitad del siglo xx, las y los jóvenes se "vuelven visibles" como resultado de la reorganización económica y la concerniente reorganización productiva, la oferta y el consumo cultural, y el discurso jurídico para protegerlas(os) o castigarlas(os) (2000, 23 y 26). A partir de esta "visibilidad" emergen los estudios de corte interpretativo-comprensivo, que problematizan a las y los jóvenes como "sujetos de discurso y con capacidad para apropiarse (y movilizar) los objetos tanto sociales y simbólicos como materiales, es decir, como agentes sociales. En otras palabras, se reconoce el papel activo de los jóvenes en su capacidad de negociación con las instituciones y estructuras" (Reguillo 2000, 36).

De la mano de este enfoque teórico metodológico, se plantea el análisis de la juventud como una construcción cultural relativa en el tiempo y el espacio. Como afirma Bourdieu, "la juventud y la vejez no son datos, sino que se construyen socialmente en la lucha entre jóvenes y viejos" $(1990,143)$. Es decir, se busca desarraigar la visión univariable de la juventud, suscribiendo la existencia de múltiples juventudes según los contextos geopolíticos, los mecanismos de socialización y ficciones orientativas que cada sociedad construye. Es decir, "cómo cada sociedad organiza la transición de la infancia a la vida adulta, la percepción social y cultural específica de estos cambios y sus repercusiones en el todo social" (Urteaga 1996).

La juventud es una construcción social y como tal histórica, política, económica y culturalmente referenciada, "no es un 'don' que se pierde con el tiempo" (Brito Lemus 1998, 3), sino un proceso de construcción simbólica donde el sujeto es actor en escenarios heterogéneos a veces interpuestos, pero siempre polisignificantes y dinámicos. Como afirma Valenzuela, "la juventud no es un campo social autocontenido, sino que se construye desde las diversas articulaciones con otras áreas de la realidad que participan en la conformación de los sentidos de la condición juvenil" (2009, 34).

Según este análisis, la juventud se concibe desde las distintas intersecciones de los procesos sociales, ubicados en una temporalidad y territorio determinado. Así que, "no existe un parámetro universal para definir y delimitar el concepto, porque las diferencias entre 
lo joven y lo no joven no se precisan a partir de un paradigma social y cultural único, así como tampoco los mecanismos para atemperar él o los conflictos generados en la permanente dialéctica entre lo que se denomina el 'mundo adulto' y el 'mundo joven"” (Zebadúa 2008, 61).

Con el fin de siglo, según Reguillo, la dialéctica mundo jovenmundo adulto se hizo más axiomática a partir de la consolidación de las industrias culturales, la difusión de medios de comunicación y supertecnologías, la exaltación del individualismo, la globalización, el discurso neoliberal, el empobrecimiento de grandes sectores de población y la deslegitimación de las instancias oficiales de participación y representación. De manera que, para entrado el siglo xxI, a partir de la mediación de estos siete procesos se han replanteado las percepciones juveniles sobre: a) la política y la visión institucional, b) el futuro y c) el espacio y la imagen de sí $(2003,114)$. Lo que se presenta en el siguiente apartado forma parte de la manera en que en la actualidad las y los jóvenes están llevando a cabo el proceso de (re)construcción de la percepción de sí, y del espacio en un territorio en y de disputa como son las ciudades fronterizas.

\section{“El otro" en los imaginarios de frontera}

Los imaginarios sociales son el conjunto de ideas, creencias y valoraciones que se definen en torno a una actividad, territorio y sociedad en un momento específico (Hiernaux 2002, 8). De manera que se entiende que están condicionados por el territorio, y que a su vez condiciona la relación del sujeto con éste (Lindón 2000); que aluden a un momento socio-histórico determinado (Castoriadis 2007, 323) y que a partir de su condición de "imágenes actuantes" (Hiernaux 2002,8 ) orientan la manera en que el sujeto se ve a sí mismo, a su entorno y su actuar en el hoy y en el futuro. En breve, son el conjunto de imágenes guías a través de las cuales se codifica y decodifica lo cotidiano, y genera expectativas para lo extraordinario.

En este apartado, a partir del análisis de algunos mapas mentales e imaginarios de frontera, se desarrolla la manera en que los sujetos 
fronterizos deTijuana yTecún Umán construyen su visión del "otro”, al otro lado de la línea. Entonces, la frontera es abordada como una institución simbólica, como un complejo material-imaginario, en tanto que hay representaciones que se construyen a partir del contacto con ella y que los símbolos adscritos a ella son interiorizados por los sujetos.

Aun y cuando la o él joven fronterizo no tenga en su círculo familiar cercano experiencia de separación, en la mayoría de los casos, el imaginario de frontera dispersadora es la primera alusión. Este imaginario está relacionado con la separación familiar, con el cruce que dispersa a las familias más allá de la congregación en territorio nacional. Para las y los tijuanenses este imaginario está sumamente arraigado, el éxodo indocumentado de jefes de familia en busca de mejores oportunidades de trabajo ha dejado -y sigue dejando- una generación juvenil que relaciona a la frontera con separación familiar. Para las y los tecunumeños, "el otro lado" no es un territorio del todo ajeno, ni difícil de acceder, no obstante, la distinción prevalece especialmente en los recursos que se pueden obtener de uno u otro lado. Y, sin embargo, esa frontera es también dispersadora; la relación comercial y laboral tan estrecha entre esta ciudad y la región del Soconusco, en territorio mexicano, ha fomentado $-y$ a veces encubierto- que algunos jefes de familia construyan una 'duplicidad' familiar al otro lado de la línea.

Para las y los jóvenes de ambas ciudades fronterizas el rostro de este imaginario está -en el caso de Tijuana-, en los agentes migratorios que rondan en patrullas la zona fronteriza o a la entrada de las garitas de control; por su parte, en Tecún Umán los perfiles son diversos, son los agentes migratorios, pero en especial son los habitantes del otro lado, los que "no respetan" (Yazmin, entrevistada en Tecún Umán, en 2009). Entonces, mientras que para las y los tecunumeños es en la relación cotidiana y extraordinaria con los 'vecinos' donde se nutre este imaginario, para las y los tijuanenses los rostros son principalmente figuras de 'autoridad'.

En tanto que establecida por condiciones político-administrativas, la alusión frontera administrativa es recalcada por las y los fronterizos. Este imaginario tiene que ver con la dimensión burocrática, es decir, la frontera es cruzable "pero hasta que te investigan hasta por 
debajo de las narices y presentas papeles, y haces todo un trámite y dicen 'bueno ok, ya te checamos y puedes cruzar', hay una cierta exclusividad” (Esperanza, entrevistada en Tijuana, en 2009).

Figura 3

Detalle del mapa mental de la frontera México-EEUU

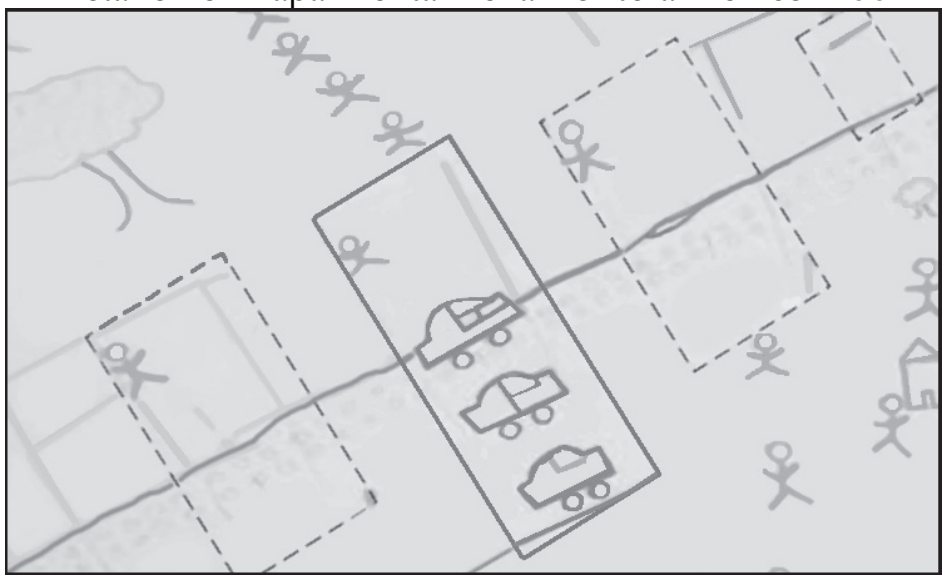

En la figura 3 es posible analizar un detalle de un mapa mental realizado por una tijuanense, donde se lee una parte importante del imaginario fronterizo en cuanto a la frontera administrativa. Las garitas que componen parte de esta dimensión están "desocupadas" -rectángulos punteados agregados para el análisis- es decir, en esta visión siempre hay espacio para el ingreso de más, sin embargo, son sólo unos cuantos los elegidos para atravesar este umbral -rectángulo continuo agregado para el análisis-.

En contraste con lo que pasa en Tijuana, en el cruce de El Talismán (a 20 minutos en vehículo de Tecún Umán), la frontera administrativa, la llamada "casa roja” del Instituto Nacional de Migración está separada del camino que transitan los transfronterizos. Aunque no es necesario pasar por ahí para entrar a México, en los mapas mentales era representada en esquina, si bien esto está relacionado con la cotidianidad transfronteriza, se vincula especialmente a que los trámites burocráticos de entrada y salida se encuentran relegados a una esquina y, entonces, sólo es necesario voltear hacia ese 
lugar en caso de que se requiera un permiso de trabajo, o algún otro trámite que implique traspasar los "límites permitidos".

Para las y los jóvenes de ambas ciudades, en este imaginario se conjugan dos aspectos fundamentales en sus referentes identitarios, el primero es que la dinámica de tránsito está impuesta por los países al norte y, por lo tanto, es considerada como arbitraria, y el segundo es que en tanto que selectiva también genera distinción al interior de suelo nacional, entre los que pueden o no cruzar la barrera. De manera que, pasar la frontera es como un bien, es algo que se atesora y se anhela cuando no se tiene. En esta premisa se sustenta el imaginario de frontera deseable. Cruzar la frontera es deseado y se da a desear, "porque el simple hecho de la prohibición lo que hace es que se vuelva objeto de deseo el estar en el otro lugar" (Jaime, entrevistado en Tijuana, en 2009). Este imaginario fue expresado por jóvenes tijuanenses que tenían opción legal de cruce y por diversas razones la perdieron, es decir, es desear $-y$ hasta cierto punto, extrañar- lo conocido, y anhelar el acceso a los recursos del otro lado. Por su parte, para las y los jóvenes tecunumeños, lo deseable de la frontera no es sólo el acceso a los recursos, sino el ir más allá, así el referente a la oficina de migración siempre está presente -figura 4: recuadro agregado para el análisis-, lo primero que se anhela al cruzar esa frontera no es el acceso a los recursos, sino la anuencia de la "libre" movilidad dentro del territorio mexicano. Entonces, se construye al "otro" como aquél que detenta el "poder de frenar o permitir movimiento" (Cresswell 2006).

Así, existe una frontera omnipresente, puesto que en el imaginario de las y los jóvenes de estas dos ciudades fronterizas, los vecinos al norte detentan el poder sobre si podrán o no acceder a recursos y mantener relaciones familiares transfronterizas. Este imaginario alude a la noción de que la infraestructura de control -helicópteros, cámaras, lámparas, aduanas, agentes migratorios, patrullas fronterizas- está siempre presente en cada kilómetro de la frontera entre los dos países -figura 5-. Está relacionado con un "escrutinio fronterizo”, es decir, es la sensación de estar vigilado a través de las bases de datos y los despliegues tecnológicos, y hacen que se desarrolle una sensación de acoso y vigilancia.

En la región Tecún Umán-Tapachula la omnipresencia de la frontera, a través de dispositivos tecnológicos, no es tan presente, sin 
embargo el "escrutinio fronterizo" está latente, de manera que se complementa esta noción con una alusión a una zona frontera. Esto en tanto que la infraestructura impuesta en línea, que divide a ambos países, no está diseñada para la contención de los contiguos a ella. Es una concepción que implica una continuidad de la noción frontera y un aumento en la infraestructura de control, conforme avanza el territorio nacional. Es bien conocido que existe cierta permisibilidad del tránsito indocumentado de la frontera sur de México, sin embargo ésta va mermándose, es decir, conforme va terminando la zona tradicional de relación transfronteriza, los retenes migratorios van en aumento.

\section{Figura 4}

Detalle del mapa mental de la frontera México-Guatemala

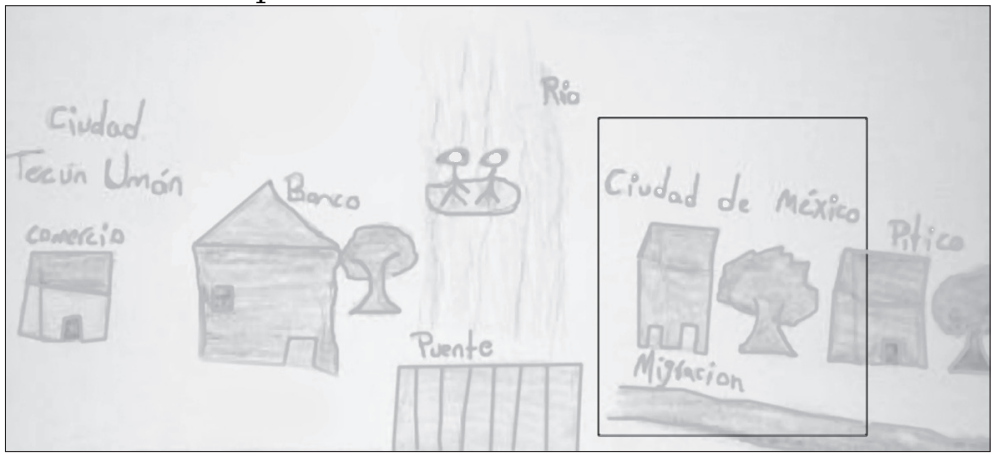

Las fronteras descritas son ante todo fronteras ambivalentes, para algunos representan la fuente de ingreso, de oportunidades laborales y educativas, mientras que para tantos otros el recordatorio constante de su imposibilidad de cruzarla. Aunque no hay que obviar el hecho de que, en el imaginario de las y los fronterizos, -a pesar de los despliegues tecnológicos y capitales humanos- la frontera es quebrantable, es decir, por y a través de ella se filtran productos e incluso personas. Para las y los jóvenes de ambas ciudades fronterizas, aun y cuando las políticas e infraestructuras de control estén dictadas desde los Estados nacionales al "norte", la relación en lo micro está guiada por las estrategias que implementan -y que se trasmiten de generación en generación- para librar estas trabas. De modo 
que la relación es de inminente confrontación, de desafío, pero, sobre todo, lo que permea las relaciones es el saber que la dinámica transfronteriza es viable porque ambos lados subsisten de ella. Así, una frontera no lo es hasta que haya alguien que no la cruce y busque cruzarla. La importancia de estos imaginarios de frontera radica en que, "como toda representación social, la representación social del territorio opera como guía potencial de las prácticas y de las decisiones" (Giménez 2007, 22).Y es en este bagaje cargado de simbolismo, cotidianidad, experiencia y relaciones sujeto-espacio donde las y los jóvenes fronterizos de ambas ciudades cimentan la construcción del "nosotros" y del "ustedes".

\section{Figura 5}

Mapa mental de la frontera México-EEUU

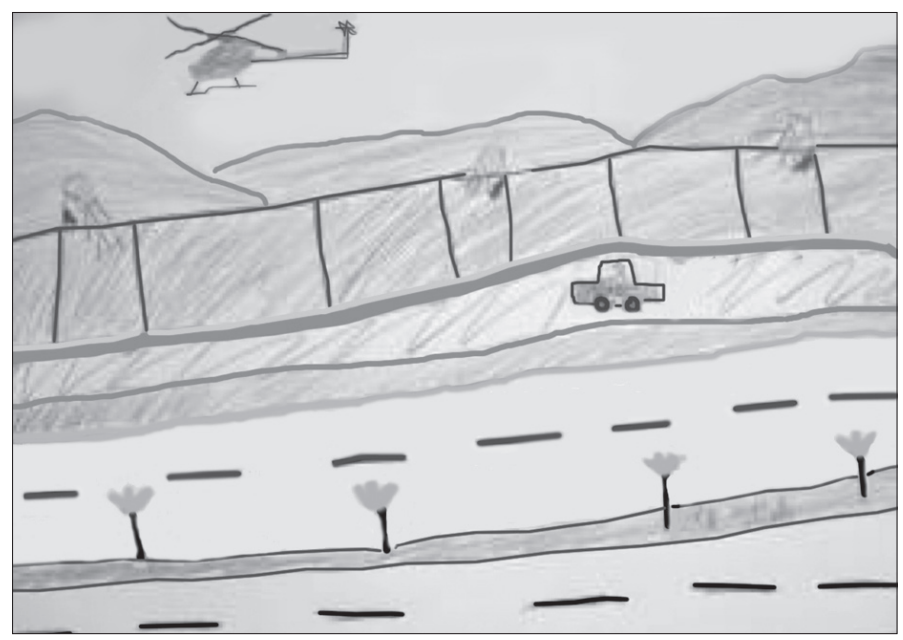

\section{Reflexiones finales}

Lo que han mostrado los mapas mentales, elaborados por las y los jóvenes de las dos ciudades fronterizas, es que los referentes que construyen de los habitantes al "otro lado" están -a pesar de la intensidad y prácticas de cruce- cargados simbólicamente de ruptura, 
más que de encuentro. No se debe olvidar que las regiones del estudio (Tijuana-San Diego, Tecún Umán-Tapachula) fueron delimitadas geopolíticamente por un proceso conflictivo para ambas, pero que recubrió con un sentimiento de pérdida para la parte sur. Es por esto que tal vez existe una resistencia permanente en la dinámica cotidiana, pequeñas dosis de liberación; para las y los tijuanenses pueden ser cubiertas con una señal obscena a los "migra" estadounidenses, o incluso cruzar a diario a trabajar con visa de turista (cambiando el peinado y vestimenta, para no ser reconocido por los agentes migratorios). Por su parte, de las prácticas que las y los tecunumeños ejercen a manera de resistencia resalta la preferencia a cruzar por balsa el río Suchiate, a pagar la cuota estipulada por los gobiernos mexicano y guatemalteco cuando se pasa por la aduana. Según su argumento, al pagar el cruce por el río, la cuota es parte del ingreso de un jefe de familia tecunumeño, de lo contrario sería un aporte a los dos gobiernos a nivel macro, y ese ingreso no tendría ninguna influencia en el nivel de vida de las y los locales.

En términos generales, se encontró una referencia común en estas juventudes fronterizas, ambas se caracterizan por tres procesos: la diferenciación/afirmación cultural, la praxis creativa y solidaria y el uso del estigma como referente identitario. El primero tiene su origen en la pluralidad de referentes identitarios -tanto del interior del país como del 'otro lado'-, con los que las juventudes fronterizas tienen contacto. Ya que las identidades son relacionales, múltiples y dinámicas, las y los jóvenes fronterizos construyen las propias a través de una amalgama de dichos referentes. El segundo, la praxis creativa y solidaria, abarca movimientos artísticos, de resistencia y de apoyo, los cuales son generados ante la necesidad de una propuesta artística que reafirme lo propio, y ante el flujo constante de personas; en este sentido las y los jóvenes han desarrollado una gran solidaridad: "Aquí todos somos un poco migrantes” (Valeria, entrevistada en Tecún Umán, en 2010). El tercero, el uso del estigma como referente identitario, alude a que tanto tijuanenses como tecunumeños -en su debida proporción-, resignifican algunos elementos de una "identidad impuesta" (Howarth 2002, 158). La mayoría se reapropia de la imagen de violencia, el flujo migratorio constante, la excentricidad y las relaciones transfronterizas como elementos identitarios por excelencia. 
El espacio fronterizo tiene muchos cristales, mejor dicho orificios, por donde mirar y significar la realidad, cada vistazo y codificación depende del pedazo de franja donde ha tocado vivir. Por su relación inmediata con su norte y su sur, las regiones fronterizas se instauran como un encapsulado con límites elásticos, para sus juventudes nada está suficientemente al norte y "para abajo" todo es el sur, de manera que sus referentes identitarios se construyen en una confrontación constante entre ser y no, entre resistir y usar.

Recibido en abril de 2011 Aceptado en octubre de 2011

\section{Bibliografía}

Allardt, Erik. 1990. Challenges for Comparative Social Research. Acta Sociológica 33 (3): 183-193.

Anderson, James y Liam O’Dowd. 1999. Borders, Border Regions and Territoriality: Contradictory Meanings, Changing Significance. Regional Studies 33 (2): 593-604.

Arriola, Aura Marina. 1995. Tapachula, "la perla del Soconusco". Ciudad estratégica para la redefinición de las fronteras. Guatemala: Facultad Latinoamericana de Ciencias Sociales (fLACSO).

Arruda, Ángela y Lilian Ulup. 2007. Brasil imaginado: representaciones sociales de jóvenes universitarios. En Espacios imaginarios y representaciones sociales. Aportes desde Latinoamérica, coordinado por ídem., y Martha de Alba, 165-198. España: Anthropos, Universidad Atuónoma Metropolitana (UAM).

Bourdieu, Pierre. 1990. La juventud sólo es una palabra. En Sociología y cultura, 142-160. México: Grijalbo, Consejo Nacional para la Cultura y las Artes (CONACULTA). 
Brito Lemus, Roberto. 2002. Identidades juveniles y praxis divergente: acerca de la conceptualización de juventud. En Jóvenes, culturas e identidades urbanas, coordinado por Alfredo Nateras Domínguez, 43-60. México: UAM, Porrúa.

1998. Hacia una sociología de la juventud. Algunos elementos para la deconstrucción de un nuevo paradigma de la juventud. Última Década 9: 1-7.

Bustamante, Jorge. 1997. Cruzar la línea. La migración de México a los Estados Unidos. México: Fondo de Cultura Económica (FCE). . 1989. Frontera México-Estados Unidos: reflexiones para un marco teórico. Frontera Norte I (1): 7-22.

Campos Delgado, Amalia E. 2010. Planeando el futuro: imaginarios de frontera y sus expresiones en la construcción de los proyectos de vida del@s jóvenes deTijuana, México y Tecún Umán, Guatemala. Tesis de maestría en estudios socioculturales. Tijuana: COLEF.

Castoriadis, Cornelius. 2007. La constitución imaginaria de la sociedad. Buenos Aires: Tusquets.

Cresswell, Tim. 2006. The Right to Mobility: The Production of Mobility in the Courtroom. Antipode 38 (4): 735-754.

Cruz Burgete, José Luis. 2006. El corredor migratorio de Tecún Umán y Ciudad Hidalgo. En Compilación de trabajos presentados en el Foro internacional de las migraciones. Tuxtla Gutiérrez: Gobierno del Estado de Chiapas/Organización Internacional para las Migraciones/ Instituto Nacional de Migración.

De Alba, Martha. 2004. Mapas mentales de la Ciudad de México: una aproximación psicosocial al estudio de las representaciones espaciales. Estudios Demográficos y Urbanos 55: 115-143.

Donnan, Hastings y Tomas M. Wilson. 2001. Borders, Frontiers of Identity, Nation and State. Oxford-Nueva York: BERG. 
Encuesta sobre migración en la frontera Guatemala-México 2007. México: Instituto Nacional de Migración/Consejo Nacional de Población/COLEF/Secretaría de Gobernación/ Secretaría del Trabajo y Previsión Social/Secretaría de Relaciones Exteriores.

Estébanez Álvarez, José. 1981. Problemas de interpretación y valoración de los mapas mentales. Anales de Geografía de la Universidad Complutense 1: 15-40.

Foucher, Michel. 2008. Retour des frontières dans le monde contemporain? Ponencia presentada en Vivre et Tracer les Frontières dans les Mondes Contemporains, Tanger.

1991. Fronts et frontières. Un tour du monde géopolitique. París: Libraire Arthème Fayard.

Giménez, Gilberto. 2007. La frontera norte como representación y referente cultural en México. Cultura y Representaciones Sociales 2 (3): 17-34.

Grimson, Alejandro. 2003. Disputa sobre las fronteras. En Teoría de frontera: los límites de la política cultural, compilado por David Johnson y Scott Michaelsen. Madrid: Gedisa.

Guerrero Tapia, Alfredo. 2007. Imágenes de América Latina y México a través de los mapas mentales. En Espacios imaginarios y representaciones sociales. Aportes desde Latinoamérica, coordinado por Ángela Arruda y Martha de Alba, 235-284. Madrid: Anthropos, UAM.

Hiernaux, Daniel. 2002. Turismo e imaginarios. En Imaginarios sociales y turismo sostenible, coordinado por ídem., Allen Cordero y Luisa Van Duynen Montijn, 7-36. Costa Rica: FLACSO.

Howarth, Caroline. 2002. Identity in Whose Eyes? The Role of Representations in Identity Construction. Journal for the Theory of Social Behaviour 32 (2): 145-162. 
INEGI. 2005. II Conteo de población y vivienda. México: INEGI.

Lindón, Alicia. 2000. La espacialidad como fuente de las innovaciones de la vida cotidiana. Hacia modos de vida cuasi fijos en el espacio. En La vida cotidiana y su espacio-temporalidad, coordinado por ídem., 187-209. Barcelona: Anthropos Editorial/El Colegio Mexiquense/Centro Regional de Investigaciones Multidisciplinarias, Universidad Nacional Autónoma de México.

, Daniel Hiernaux y Miguel Aguilar. 2006. De la espacialidad, el lugar y los imaginarios urbanos: a modo de introducción. En Lugares e imaginarios en la metrópolis, coordinado por ídem., 9-25. Madrid: Anthropos, UAM.

Luján Muñoz, Jorge. 1998. Breve historia contemporánea de Guatemala. México: FCE.

Margulis, Mario. 2001. Juventud: una aproximación conceptual. En Adolescencia y juventud en América Latina, compilado por Solum Donas Burak, 41-56. Cartago: Libro Universitario Regional.

Monsiváis Carrillo, Alejandro. 2004. Tijuana trips. Relatos en torno a la relación de la ciudadanía entre jóvenes de la frontera noreste de México. Jóvenes, Revista de Estudios sobre Juventud 8 (21): 6-25.

Muhr, Thomas. 1991. ATLaS/ti-A Prototype for the Support of Text Interpretation. Qualitative Sociology 14 (4): 349-7 1.

Newman, David. 2006a. Borders and Bordering. Toward an Interdisciplinary Dialogue. European Journal of Social Theory 9 (2): 171-186.

. 2006b. The Lines that Continue to Separate us: Borders in Our 'Borderless' World. Progress in Human Geography 30 (2): 143 161.

Nolasco, Margarita, Virginia Molina, Ma. Luisa Acevedo, Iván Roldán, Miguel A. Bravo y Salustia Merino. 1992. Brevario de los munici- 
pios fronterizos de México. México: Ed. Paraná/Centro de Ecodesarrollo/Centro Nacional de Desarrollo Municipal.

Odgers, Olga. 2006. Cambio religioso en la frontera norte. Aportes al estudio de la migración y las relaciones transfronterizas como factores de cambio. Frontera Norte 18 (35): 111-134.

2001. Identités fontenières. Immigrés mexicains aux États-Unis. París: L'Harmattan.

Ojeda, Norma. 2009. Reflexiones acerca de las familias transfronterizas y las familias transnacionales entre México y Estados Unidos. Frontera Norte 21 (42): 7-30.

Ragin, Charles C. 2007. El uso de los métodos comparativos para estudiar la diversidad. En La construcción de la investigación social, 177 212. Bogotá: Siglo del Hombre Editores/Universidad de Los Andes.

Reguillo, Rossana. 2003. Las culturas juveniles: un campo de estudio; breve agenda para la discusión. Revista Brasileira de Educação 23: 103-118.

2000. Emergencia de culturas juveniles. Estrategias del desencanto. Buenos Aires: Editorial Norma.

Silva, Armando. 2006. Imaginarios urbanos: hacia el desarrollo de un urbanismo de los ciudadanos. Metodología. Bogotá: Convenio Andrés Bello/Universidad Nacional de Colombia.

Torpey, John. 1998. Coming and Going: On the State Monopolization of the Legitimate 'Means of Movement. Sociological Theory 16 (3): 239-259.

Urteaga Castro Pozo, Maritza. 1996. Flores de asfalto. Las chavas en las culturas juveniles. Jóvenes, Revista de Estudios sobre Juventud IV-I (2): $50-65$. 
Valenzuela Arce, José Manuel. 2009. El futuro ya fue. Socioantropología de $1 @$ @ jóvenes en la modernidad. México: Colef, Casa Juan Pablos.

. 2005. La carpa sobre el asfalto. La antropología urbana en la(s) frontera(s) mexicana(s). En La antropología urbana en México, coordinado por Néstor García Canclini, 221-261. México: FCE.

2003. Centralidad de las fronteras. Procesos socioculturales en la frontera México-Estados Unidos. En Por las fronteras del norte. Una aproximación cultural a la frontera México-Estados Unidos, coordinado por ídem, 33-67. México: CONACULTA, FCE.

2000. Norteños ayancados. Discursos y representaciones de la frontera. Comunicación y Sociedad 38: 37-57.

Vila, Pablo. 2008. Procesos identificatorios en la frontera entre México y Estados Unidos. En Migración, fronteras e identidades étnicas transnacionales, coordinado por Laura Velasco, 303-326. México: COLEF, Porrúa.

. 2000. Crossing Borders, Reinforcing Borders: Social Categories, Metaphors, and Narrative Identities on the U.S.-Mexico Frontier. Texas: University of Texas Press.

Wilson, Thomas M., y Hastings Donnan. 1998. Nation, State and Identity at International Borders. En Border Identities- Nation and State at International Frontiers, editado por ídem., 1-30. Cambridge: Cambridge University Press.

Zebadúa Carbonell, Juan Pablo. 2008. Culturas juveniles en contextos globales. Estudio sobre la construcción de los procesos identitarios de las juventudes contemporáneas. Tesis de doctorado en sociedades multiculturales y estudios interculturales, Universidad de Granada-Universidad Veracruzana.

Zúñiga, Erik. 2010. Monografía del municipio de Ayutla. Departamento de San Marcos, municipalidad Tecún Umán. 